\title{
Correction to: Between Economic Development and Human Rights: Balancing E-Commerce and Adult Content Filtering
}

Adam Szafrański, Piotr Szwedo and Małgorzata Klein

\section{Correction to:}

Chapter 9 in: P. Szwedo et al. (eds.), Law and Development, Kobe University Monograph Series in Social Science Research, https://doi.org/10.1007/978-981-13-9423-2_9

In the original version of this book, the following change has been made: In the chapter 9, the affiliation "Faculty of Law and Administration, University of Warsaw" of the author "Małgorzata Klein" has been changed to "Faculty of Geography and Regional Studies, University of Warsaw." The erratum chapter has been updated with the changes. 